\title{
Yüksek Centor Skorunu Belirlemede Hemogram Parametrelerinin Kullanımı
}

\author{
The Usage of Hemogram Parameters for Determining High Centor Score
}

Ceyhun Cengiz

Yozgat Bozok Üniversitesi Tip Fakültesi Kulak Burun Boğaz Anabilim Dalı, Yozgat, Türkiye

Correspondence:

Ceyhun CENGİZ

Yozgat Bozok Üniversitesi Tip Fakültesi Kulak Burun Boğaz Anabilim Dalı, Yozgat, Türkiye e-mail: cyhncngz@gmail.com

\section{Özet}

Modifiye Centor Kriterleri bakteriyel-viral tonsilofaranjit ayrımında sıklıkla kullanılmaktadır. Bu puanlama sistemi anamnez ve fizik muayene bulguları gibi subjektif verilere dayanmaktadır. Bu çalışmada yüksek centor skorunu belirlemede hemogram parametrelerinin kullanımı araştırılmıştır. 01/01/2019-31/12/2019 tarihleri arasında boğaz ağrısı şikayeti ile kulak burun boğaz polikliniğine başvurmuş ve akut tonsilofaranjit tanısı alan hastalar retrospektif olarak tarandı. Bu hastalardan bu bașurularında hemogram tetkiki istenmis olanlar çalışmaya dahil edildi. Tüm hastaların kayıtlı anamnez ve fizik muayene bulguları incelenerek modifiye centor skoru hesaplandı. Centor skoru 4 olanlar yüksek centor grubunu oluştururken, centor skoru 0 ve 1 olanlar düşük centor grubunu oluşturdu. Herbir grupta 30 hastanın olması sağlandı. İki grup hemogram parametreleri açısından karșılaștırıldı. Ortalama beyaz küre sayısı, nötrofil sayısı, monosit sayısı yüksek centor grubunda $(10.96 \pm 3.49,7.91 \pm 3.43,1.06 \pm 0.34$, sirasıyla) düsük centor grubundan $(7.94 \pm 2.11,5.10 \pm 1.94,0.66 \pm 0.23$, sirasıyla) daha yüksek saptanmıștır. Bu farklar istatistiksel olarak anlamlıdır ( $<<0.001, \mathrm{p}<0.001, \mathrm{p}<0.001$,sırasıyla). Yüksek centor grubunda saptanan ortalama MCV ve MPV değerleri $(84.17 \pm 5.48,9.44 \pm 0.99$, sırasıyla) düşük centor grubunda saptanan değerlerden $(86.89 \pm 4.49,10.14 \pm 0.78$, sırasıyla) daha düsüktür. Bu farklar da istatistiksel olarak anlamlıdır ( $\mathrm{p}=0.008, \mathrm{p}=0.004$, sırasıyla). Ayrıca ortalama RDW değeri yüksek centor grubunda (13.88 \pm 1.44$)$ düşük centor grubuna göre (13.06 \pm 0.92$)$ daha yüksek bulunmuştur $(\mathrm{p}=0.012)$. Hesaplanan veriler incelendiğinde ortalama nötrofil-lenfosit oranı ve ortalama monosit-lenfosit oranı yüksek centor grubunda $(5.25 \pm 4.41,0.62 \pm 0.21$, sırasıyla) düşük centor grubuna göre $(3.17 \pm 3.04,0.39 \pm 0.24$, sırasıyla) daha yüksek saptanmıştır $(\mathrm{p}<0.001, \mathrm{p}<0.001$, sırasıyla). Hemogram parametreleri hem yüksek centor skorunu belirlemede hem de akut tonsilofaranjit etiyolojisinde bakteriyel-viral ayrımını yapmakta kullanılabilir. Hemogram parametrelerinin modifiye centor puanlama sistemiyle birlikte kullanımı bu puanlama sisteminin duyarlılık ve özgüllüğünü arttırabilir.

Anahtar Kelimeler: Modifiye centor skoru; hemogram; akut tonsilofaranjit; grup A streptokok

\section{Abstract}

Modified Centor Criteria are frequently used to differantiate bacterial-viral tonsilopharyngitis. This scoring system is based on subjective data such as history and physical examination. In this study, the use of hemogram parameters in determining high centor score was investigated. Patients who applied to otolaryngology outpatient clinic with complaint of sore throat between 01/01/2019-31/12/2019 and were diagnosed with acute tonsilopharyngitis were retrospectively scanned. Of these patients, those who were requested to have hemogram at their admission were included in study. Modified centor score was calculated by examining recorded anamnesis and physical examination. Those with a centor score of 4 formed high centor group, while those with a centor score 0 and 1 formed low centor group. It was ensured that there were 30 patients in each group. Two groups were compared in terms of hemogram parameters. Mean white blood cell, neutrophil and monocyte counts were higher in high centor group $(10.96 \pm 3.49,7.91 \pm 3.43,1.06 \pm 0.34$, respectively) than in low centor group $(7.94 \pm 2.11$, $5.10 \pm 1.94,0.66 \pm 0.23$, respectively). These differences are statistically significant $(\mathrm{p}<0.001, \mathrm{p}<0.001, \mathrm{p}<0.001$, respectively). Mean MCV and MPV values found in high centor group $(84.17 \pm 5.48,9.44 \pm 0.99$, respectively) were lower than values found in low centor group $(86.89 \pm 4.49,10.14 \pm 0.78$, respectively). These differences are also statistically significant $(\mathrm{p}=0.008, \mathrm{p}=0.004$, respectively). In addition, mean RDW value was found to be higher in high centor group $(13.88 \pm 1.44)$ than in low centor group $(13.06 \pm 0.92, p=0.012)$. When calculated data were analyzed, mean neutrophil-lymphocyte and monocyte-lymphocyte ratios were found to be higher in high centor group (5.25 \pm 4.41 , $0.62 \pm 0.21$, respectively) than in low centor group $(3.17 \pm 3.04,0.39 \pm 0.24, \mathrm{p}<0.001, \mathrm{p}<0.001$, respectively). Hemogram parameters can be used both to determine high centor score and to differentiate bacterial and viral etiology in acute tonsilopharyngitis. Usage of hemogram parameters together with modified centor scoring system can increase sensitivity and specificity of this scoring system.

Keywords: Modified centor score; hemogram; acute tonsilopharyngitis; group A streptococcus 


\section{Giriş}

Akut tonsilofaranjit tedavisinde etiyolojide bakteriyel-viral ayrımını yapmak en kritik basamaktır. Bakterilere bağlı meydana gelen tonsilofarenjitlerin tedavisinde antibiyotikler kullanılırken virüslere bağlı meydana gelen tonsilofarenjitlerin tedavisinde semptomatik tedavi uygulanmaktadır. Bakteriyel tonsilofaranjitlerin özellikle grup A beta hemolitik streptokokların (GABHS) antibiyotik ile tedavi edilmesi, hem süpüratif komplikasyonların hem de akut romatizmal ateş, akut glomerülonefrit gibi non süpüratif komplikasyonların önlenmesi açısından önemlidir (1). Bu nedenle akut tonsilofaranjit etiyolojisinde bakteriyel-viral ayrımını yapmak en kritik basamaktır. Bu amaçla GABHS tanısının klinik ve epidemiolojik bulgularla beraber labaratuar testlerine dayandırılması önerilmektedir (2). Modifiye Centor Kriterleri bu amaçla kullanılan fizik muayene ve anamnez bulgularına dayanan puanlama sistemlerinden biridir. Bu puanlama sistemi ile elde edilen puanlarn artmasiyla beraber hastada GABHS'a bağl1 tonsilofaranjit görülme riski de artmaktadır $(3,4)$. Bu puanlama sistemi anamnez ve fizik muayene bulgularına dayanmaktadır, bu nedenle subjektiftir. Boğaz kültürü ve hızlı antijen testleri daha objektif testler olmasina karşın bu tetkikler hem daha uzun sürede sonuçlanmaktadırlar hem de daha maliyetlidirler. $\mathrm{Bu}$ nedenle akut tonsilofaranjit etiyolojisinde bakteriyel-viral ayrımını yapmakta kullanılabilecek objektif ve düşük maliyetli tetkiklere ihtiyaç duyulmaktadır.

Hemogram tetkiki birçok patolojinin tanı ve takibinde siklıkla kullanılan basit, kolay ulaşlabilir ve ucuz bir tetkiktir. Bu nedenle bu tetkiki akut tonsilofaranjit etiyolojisinde bakteriyel-viral ayrımını yapmak amaciyla kullanmak mantıklı görünmektedir. Hemogram tetkikinde incelenen birçok parametre bu amaçla kullanılabilir. Eğer bu parametrelerden bazıları yüksek centor skorunu belirlemede faydalı bulunursa bakteriyel-viral tonsilofaranjit ayrımında da kullanılabilecektir. Ayrıca yüksek centor skorunun hemogram tetkiki ile desteklenmesi bu puanlama sisteminin duyarlılık ve özgüllüğünü de arttırabilir.

Bu çalışmada yüksek Modifiye Centor Skoru olan hastalar düşük skoru hastalar ile hemogram parametreleri açısından karşılaştırılmıştır

\section{Gereç ve Yöntemler}

$\mathrm{Bu}$ çalışma lokal etik kurul onayı alındıktan sonra üçüncü basamak bir hastanenin kulak burun boğaz bölümünde yapıldı (Karar No:2017-KAEK-189 2021.09.22 07).

01/01/2019-31/12/2019 tarihleri arasinda kulak burun boğaz polikliniğine başvurmuş ve akut tonsilofarenjit tanısı alan hastalar hastane otomasyon sisteminden tarand. $\mathrm{Bu}$ hastalardan bu başvurusunda hemogram tetkiki istenmiş olanlar çalışmaya dahil edildi. Hastaların otomasyon sisteminden elde edilen anamnez bilgilerine ve fizik muayene bulgularına göre Modifiye Centor Skoru belirlendi. Modifiye Centor Skoru yüksek olan hastalar Modifiye Centor Skoru düşük olan hastalar ile hemogram parametreleri açısından karșılaștırıldı. Herbir grupta 30 hasta olacak şekilde toplam 60 hasta çalışmaya dahil edildi. Hematolojik hastalığ 1 olanlar, kronik hastalığ olanlar, hemogram parametrelerini etkileyebilecek ilaç kullanım öyküsü olanlar, malignitesi olanlar, kronik akciğer ve kalp hastalığı olanlar, 18 yaşından küçükler, 65 yaşından büyükler çalışmaya dahil edilmedi. Başvuru sırasında hastaların akut tonsilofaranjit için herhangi bir tedavi almiyor oldukları teyit edildi. Hastaların 32'si kadın iken, 28'i erkekti. Hastaların yaş ortalamas1 $32.42 \pm 12.69$ saptand. İki grup arasında yaş ve cinsiyet açısından istatistiksel olarak anlamlı bir fark yoktu (Tablo 1). Hastaların tüm demografik verileri Tablo 1' de verilmiştir. 
Tablo 1. Çalışmaya dahil edilen hastaların demografik verileri

\begin{tabular}{|c|c|c|c|}
\hline & Yüksek Centor Grubu & Düşük Centor Grubu & $p$ \\
\hline \multicolumn{4}{|l|}{ Cinsiyet } \\
\hline Erkek & 16 & 12 & $0.301^{\mathrm{a}}$ \\
\hline Kadın & 14 & 18 & \\
\hline Yaş & $30.00 \pm 8.37$ & $34.83 \pm 15.67$ & $0.143^{b}$ \\
\hline \multicolumn{4}{|c|}{$\begin{array}{l}\text { Centor Puanına } \\
\text { Göre Hasta } \\
\text { Dağılımı }\end{array}$} \\
\hline 0 puan & & 14 hasta & \\
\hline 1 puan & & 16 hasta & \\
\hline 4 puan & 30 hasta & & \\
\hline
\end{tabular}

Modifiye Centor Kriterleri akut tonsilofaranjit tanıs1 alan hastalarda bakteriyel ve viral etiyolojiyi ayırmak amaciyla kullanılan, anamnez ve fizik muayene bulgularına dayanan bir puanlama sistemidir. $\mathrm{Bu}$ puanlama sisteminde 5 kriter puanlanmaktadır. Bu puanlama sistemine göre ateşin $38^{\circ} \mathrm{C}$ nin üzerinde olmas +1 puan, hastada ağrılı büyümüş ön servikal LAP'ların olmas1 +1 puan, tonsillerde hipertrofi veya eksuda olmas $1+1$ puan, öksürük bulunmamas1 +1 puan, yaşın 3-14 yaş arasında olması +1 puan, 15-44 yaş arasında olması 0 puan, 44 yaşın üzerinde olması -1 puan olarak puanlanır (Tablo 2). Bu puanlama sonucunda elde edilen toplam puan arttıkça akut tonsilofaranjitin GABHS'a bağlı meydana gelme ihtimali de artmaktadır (4). Bu nedenle yüksek centor skorlu hastaların antibiyotikle tedavi edilmesi önerilirken düşük centor skorlu hastalara semptomatik tedavi verilir. $\mathrm{Bu}$ çalışmada da yüksek Modifiye Centor Skoru olan hastalar (toplam puanı 4 olanlar), düşük Modifiye Centor Skoru olan hastalar ile (toplam puan1 0 veya 1 olanlar) hemogram parametreleri açısından karşılaştırılmıştır. Yüksek centor skorunu belirlemede hemogram parametrelerinin kullanılabilirliği araştırılmıştır.

Table 2. Modifiye centor kriterleri ve puanlamas1

\begin{tabular}{ll}
\hline Kriterler & Puan \\
\hline Ateş $\left(\mathbf{3 8}^{\circ} \mathbf{C}<\right)$ & +1 puan \\
Ağrılı büyümüs ön servikal LAP & +1 puan \\
\hline Tonsillerde hipertrofi veya eksuda & +1 puan \\
Öksürüğün bulunmaması & +1 puan \\
Yaş & \\
$\quad \mathbf{3 - 1 4}$ yaş arası & +1 puan \\
\hline $\mathbf{1 5 - 4 4}$ yaş arası & 0 puan \\
\hline $\mathbf{4 4}$ yaș üstü & -1 puan \\
\hline
\end{tabular}

\section{İstatistiksel Analiz}

İstatistiksel analiz Statistical Package for Social Sciences (SPSS) version 15 kullanılarak yapıldı. Değişkenlerin normal dağılıp dağılmadığına karar vermek için görsel (histogram, probability plots) ve analitik metodlar (Kolmogorov-Simirnov testi) kullanıldı. İki grubun hemogram parametreleri Mann Whitney-U testi/
Bağımsız Gruplar T-testi kullanılarak karşılaştırıldı. İki gruptaki kategorik verilerin karşılaştırılmasında Pearson Ki-Kare testi kullanıld. $\mathrm{p}<0.05$ istatistiksel olarak anlaml kabul edildi. 


\section{Bulgular}

Yüksek Centor grubunda ortalama beyaz küre sayıs1 10.96 3.49 iken Düşük Centor grubunda ortalama beyaz küre sayıs1 $7.94 \pm 2.11$ saptanmıştır. Yüksek Centor grubunda ortalama nötrofil sayıs1 $7.91 \pm 3.43$ iken Düşük Centor grubunda ortalama nötrofil

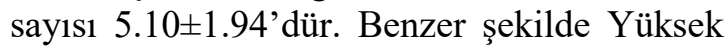
Centor grubunda Düşük Centor grubuna göre daha yüksek ortalama monosit sayısı elde edilmiştir $(1.06 \pm 0.34, \quad 0.66 \pm 0.23$, sırayla). Tüm bu farklar istatistiksel olarak anlamlı bulunmuştur $(\mathrm{p}<0.001, \mathrm{p}<0.001, \mathrm{p}<0.001$, sirayla, Tablo 3)
Yüksek Centor grubunda ortalama MCV değeri $84.17 \pm 5.48$ iken Düşük Centor grubunda ortalama MCV değeri $86.89 \pm 4.49$ saptanmıştır. $\mathrm{Bu}$ fark istatistiksel olarak anlamlıdır ( $\mathrm{p}=0.008$, Tablo 3). Benzer şekilde Yüksek Centor grubunda ortalama MPV değeri $9.44 \pm 0.99$ iken Düşük Centor grubunda ortalama MPV değeri $10.14 \pm 0.78$ bulunmuştur. $\mathrm{Bu}$ fark da istatistiksel olarak anlamlı bulunmuştur $(\mathrm{p}=0.004$, Tablo 3$)$. Yüksek Centor grubunda (13.88 1 1.44) Düşük Centor grubuna $(13.06 \pm 0.92)$ göre daha yüksek ortalama RDW değeri saptanmıştır. $\mathrm{Bu}$ fark istatistiksel olarak anlamlıdır $(\mathrm{p}=0.012$, Tablo 3).

Tablo 3. Yüksek ve düşük centor grubunun hemogram parametreleri açısından karşılaştırılması

\begin{tabular}{|c|c|c|c|}
\hline & $\begin{array}{c}\text { Yüksek Centor Grubu } \\
(M e a n \pm \text { SD })\end{array}$ & $\begin{array}{c}\text { Düşük Centor Grubu } \\
(\text { Mean } \pm \text { SD) }\end{array}$ & $P$ \\
\hline Beyaz Küre Sayısı & $10.96 \pm 3.49$ & $7.94 \pm 2.11$ & $<0.001^{\mathrm{a} *}$ \\
\hline Nötrofil Sayısı & $7.91 \pm 3.43$ & $5.10 \pm 1.94$ & $<0.001^{\mathrm{b} *}$ \\
\hline Lenfosit Sayısı & $1.83 \pm 0.72$ & $1.99 \pm 0.76$ & $0.423^{\mathrm{a}}$ \\
\hline Monosit Sayısı & $1.06 \pm 0.34$ & $0.66 \pm 0.23$ & $<0.001^{\mathrm{a} *}$ \\
\hline Eritrosit Sayısı & $5.05 \pm 0.34$ & $4.83 \pm 0.49$ & $0.053^{\mathrm{a}}$ \\
\hline Hemoglobin Değeri & $14.32 \pm 1.59$ & $13.90 \pm 1.49$ & $0.301^{\mathrm{a}}$ \\
\hline Hematokrit Değeri & $42.54 \pm 4.13$ & $42.05 \pm 3.74$ & $0.636^{\mathrm{a}}$ \\
\hline $\begin{array}{l}\text { Mean Corpuscular } \\
\text { Volume (MCV) }\end{array}$ & $84.17 \pm 5.48$ & $86.89 \pm 4.49$ & $0.008^{\mathrm{b} *}$ \\
\hline $\begin{array}{l}\text { Red Cell Distribution } \\
\text { Width (RDW) }\end{array}$ & $13.88 \pm 1.44$ & $13.06 \pm 0.92$ & $0.012^{\mathrm{a} *}$ \\
\hline Platelet Sayısı & $248.53 \pm 88.16$ & $255.13 \pm 53.60$ & $0.728^{\mathrm{a}}$ \\
\hline $\begin{array}{c}\text { Mean Platelet Volume } \\
\text { (MPV) }\end{array}$ & $9.44 \pm 0.99$ & $10.14 \pm 0.78$ & $0.004^{\mathrm{a} *}$ \\
\hline $\begin{array}{c}\text { Platelet Distribution } \\
\text { Width (PDW) }\end{array}$ & $11.25 \pm 1.47$ & $11.62 \pm 1.68$ & $0.420^{\mathrm{b}}$ \\
\hline Nötrofil/Lenfosit & $5.25 \pm 4.41$ & $3.17 \pm 3.04$ & $<0.001^{\mathrm{b} *}$ \\
\hline Platelet/Lenfosit & $151.41 \pm 74.98$ & $143.27 \pm 59.73$ & $0.779^{\mathrm{b}}$ \\
\hline Monosit/Lenfosit & $0.62 \pm 0.21$ & $0.39 \pm 0.24$ & $<0.001^{\mathrm{b} *}$ \\
\hline
\end{tabular}

Hesaplanan veriler incelendiğinde Yüksek Centor grubunda ortalama nötrofil-lenfosit oranı $5.25 \pm 4.41$ iken, Düsük Centor grubunda ortalama nötrofil-lenfosit oran1 $3.17 \pm 3.04$ saptanmıştır. Yüksek Centor grubunda ortalama monosit-lenfosit oranı $0.62 \pm 0.21$ iken Düşük Centor grubunda ortalama monosit-lenfosit oran $10.39 \pm 0.24$ 'dir. $\mathrm{Bu}$ farklar istatistiksel olarak anlaml bulunmuştur $(\mathrm{p}<0.001, \quad \mathrm{p}<0.001, \quad$ sirayla, Tablo 3). Platelet-lenfosit oranı açısından
Yüksek Centor grubu (151.41 \pm 74.98$)$ ve Düşük Centor grubu (143.27 \pm 59.73$)$ arasında fark saptanmamıştır ( $\mathrm{p}=0.779$, Tablo 3 ).

İki grup arasında lenfosit sayısı, eritrosit sayıs1, hemoglobin değeri, hemotokrit değeri, platelet sayısı, PDW değeri açısından istatistiksel olarak anlamlı bir fark saptanmamıştır ( Tablo 3). 


\section{Tartışma}

Akut tonsilofaranjitler çoğunlukla virüslere bağlı meydana gelmekle birlikte bakteriler de akut tonsilofaranjit oluşumunda rol oynarlar (5). Bakteriyel tonsilofaranjitlerin büyük çoğunluğu GABHS nedeniyle oluşur (6). GABHS tedavisi romatizmal ateşin ve süpüratif komplikasyonların önlenmesi, semptomların azaltılması, hastalığın yayılımının önüne geçilmesi açısından önemlidir (7). $\mathrm{Bu}$ nedenle bakteriyel tonsilofaranjitlerin antibiyotik ile tedavi edilmesi gerekirken viral tonsilofaranjitlerin tedavisinde semptomatik tedavi yeterlidir. Akut tonsilofaranjit tedavisinde bakteriyelviral ayrımını yapmak en önemli basamaktır. $\mathrm{Bu}$ ayrımı yapmakta çeşitli tetkikler ve puanlama sistemleri kullanılmaktadır. Streptokokkal tonsilofaranjit tanısını koymak için hızlı antijen testi ve/veya boğaz kültürü ile beraber klinik tanı kriterlerinin kullanılması önerilmektedir (8). Öte yandan birçok çalışmada yüksek Centor skoru ile direkt ampirik antibiyotik tedavisinin başlanması gerektiği ileri sürülmektedir $(5,9)$. Yani tüm Centor Kriterlerinin puan alması durumunda ampirik antibiyotik başlanması geçerli ve yaygın bir uygulamadır (10). Ayrica centor puanlama sisteminin kullanılması uygun antibiyotik kullanımını arttırmakta ve antibiyotik kullanım oranını azaltmaktadır (10). Boğaz kültürü bakteriyelviral etiyolojiyi ayırdetmekte kullanılan altın standart yöntemdir. Fakat boğaz kültüründe patojenlerin üremesi 48 saati bulabilmektedir (6). $\mathrm{Bu}$ da tedavinin gecikmesine yol açmaktadır. Özellikle gelişmiş ülkelerde bakteriyel-viral tonsilofaranjit ayrımında hızlı antijen testleri kullanılmaktadır. Bu testlerin literatürede sensitivite oranları ile ilgili değişik sonuçlar verilse de hızlı sonuç vermesi en büyük avantajıdır (6). Fakat bu testlerin de maliyetinin yüksek olması özellikle gelişmemiş ve gelişmekte olan ülkelerde kullanımının önünde önemli bir engeldir (6). Ayrıca çalışmalar boğazdan örnek alınmasının tonsilofaranjit tedavisinde yaygin olarak kullanılmadığını göstermektedir (10). $\mathrm{Bu}$ nedenle maliyeti olmayan, hastanın anamnez ve fizik muayene bulgularına dayanan Modifiye Centor Kriterleri gibi puanlama sistemleri akut tonsilofaranjit tedavisinde bakteriyel-viral ayrımını yapmakta sıklıkla kullanılmaktadır. Çalışmalarda, hekimlerin akut tonsilofaranjitin GABHS'lara bağlı olup olmadığını bilmeksizin sadece klinik özellikleri değerlendirerek antibiyotik yazma eğiliminde oldukları ileri sürülmektedir (11). Centor puanlama sistemi akut tonsilofaranjitli hastalarda GABHS riskini belirlemek amaciyla kullanılmaktadır (7). Centor Kriterleri 1981 yılında ilk defa yayınlandıktan sonra 1998 y1linda Modifiye Centor Kriterleri oluşturulmuştur (12,13). Modifiye Centor Kriterleri'nde diğer adıyla Mc Isaac Kriterleri' nde Centor Kriterlerine ek olarak hastanın yaşı da puanlamaya dahil edilmektedir. Böylelikle Centor Kriterleri'nde maksimum alınabilen puan 4 iken Modifiye Centor Kriterleri'nde maksimum alınabilen puan 5 olmuştur. Çalışmamızda dahil edilen hastaların tamamının 18-44 yaş aralığında olması nedeniyle tüm hastalar bu bölümden 0 puan almıştır bu nedenle çalışmamızda her iki puanlama sistemine göre de maksimum alınan puan 4 olmuştur. Yüksek Centor Grubunu centor skoru 4 olan hastalar oluştururken, Düşük Centor Grubunu centor skoru 0 ve 1 olan hastalar oluşturmuştur. Daha önce de belirtildiği gibi Modifiye Centor Puanlama Sistemi hastanın anamnez ve fizik muayene bulgularına dayanmaktadır. Literatürde yapılan bir çalışmada ateş ve öksürük yokluğu gibi hastanın anamnezine dayalı öğelerin puanlamasinın hasta veya ebeveynleri ile doktorlar arasında benzer olduğu saptanmıştır. Öte yandan boyunda ağrilı lenf nodu ve tonsiller eksuda gibi fizik muayene bulgularına dayanan öğelerin puanlamasının hasta veya ebeveynleri ile doktorlar arasinda daha az benzer olduğu ortaya konmaktadır (7). Ayrica bu kriterlerin herbirinin GABHS tanısinı koymada veya ekyartasyonundaki etkisi farklı bulunmuştur (14). Bu da diğer tetkiklere nazaran Modifiye Centor Puanlama sisteminin daha subjektif olduğunu gösterir. $\mathrm{Bu}$ nedenle siklıkla hizlı antijen testiyle veya boğaz kültürü ile doğrulanması önerilir. Çalışmamızda da yüksek centor skorunu belirlemede hemogram parametrelerinin kullanımı araştırılmıştır. Yüksek Centor grubunda Düşük Centor grubuna göre daha yüksek beyaz küre sayıs1, nötrofil sayıs1, 
monosit sayısı ve RDW değeri elde edilirken, daha düşük MCV ve MPV değerleri elde edilmiştir. Önceki çalışmalar centor skorunun artmasıyla GABHS pozitifliğinin arttığını ortaya koymaktadır (7). Yüksek Centor grubunda bakteriyel tonsilofaranjit sayısı daha fazla olacağından beyaz küre sayısında ve nötrofil sayısında daha yüksek değerler elde etmek şaşırtıcı değildir. Öte yandan Yüksek Centor grubunda daha yüksek monosit, RDW değerleri ve daha düşük MCV, MPV değerleri elde edilmiştir. Bu bulgular literatür için yeni bulgulardır. Tüm bu parametreler yüksek centor skorunu belirlemek veya teyit etmek amaciyla kullanılabilir. Ayrıca hemogram parametrelerinden yararlanilarak hesaplanan nötrofil-lenfosit oran1, monosit-lenfosit oranı da yüksek centor grubunda daha yüksek saptanmıștır. $\mathrm{Bu}$ veriler de bakteriyal-viral tonsilofaranjit ayrımında kullanılabilir.

Yukarıda da belirtilen kısıtlılıklar nedeniyle akut tonsilofaranjitte bakteriyel-viral ayrımını boğaz kültürü veya hızlı antijen testleriyle yapmak her zaman mümkün olmamaktadır. $\mathrm{Bu}$ nedenle Modifiye Centor Puanlama sistemi klinisyenler tarafindan siklıkla tercih edilmektedir. Öte yandan Modifiye Centor Kriterleri'nde ateş, boyunda ağrilı lap, öksürük olmaması gibi puanlanan kriterler siklıkla hastanın beyanına dayanmaktadır. $\mathrm{Bu}$ da puanlamanın subjektif olmasina neden olmaktadır. Ayrıca Shaikh ve ark. yaptıkları çalışmada hiçbir puanlama sisteminin mikrobiyolojik inceleme ihtiyacını ortadan kaldıracak düzeyde yeterince sensitivitesinin ve spesifitesinin olmadığını ortaya

\section{REFERENCES}

1. Cag Y, Özdemir AA, Yükselmiş U et al. Association between rapid antigen testing and antibiotic use and accuracy of peripheral blood parameters in detecting group a streptococcus in children with tonsillopharyngitis. Frontiers In Pediatrics. 2019;7:322.

2. Schwartz B, Marcy SM, Phillips WR et al. Pharyngitis-principles of judicious use of antimicrobialagents. Pediatrics. 1998;101(Supplement 1):171-174

3. McIsaac WJ, Kellner JD, Aufricht $\mathrm{P}$ et al Empirical validation of guidelines for the koymaktadır (15). Bu nedenle bu subjektif puanlama sisteminin daha objektif tetkiklerle doğrulanması ve sensitivite/spesifitesinin arttırılması gerekmektedir. $\mathrm{Bu}$ çalışmada hemogram tetkikinin yüksek centor skorunu belirlemede kullanılması araştırılmıştır. Gelecek çalışmalarda yüksek centor skorunu belirlemede başka tetkiklerin de etkisinin araştırılması literatüre bu konuda katk1 sağlayacaktır. Hatta gelecek çalışmalarda Centor gibi puanlama sistemlerine hemogram gibi basit objektif tetkikler eklenerek sensitivitesi ve spesifitesi daha güçlü olan puanlama sistemleri oluşturulabilir.

Çalışmamızda yüksek centor grubunu centor skoru 4 olan hastalar oluştururken, düşük centor grubunu centor skoru 0 veya 1 olan hastalar oluşturmuştur. İki grubun skor olarak birbirine yakın olmaması iki grubun klinik olarak da belirgin farklı olmasını sağlamıştır. $\mathrm{Bu}$ çalışmamızın güçlü tarafı olarak görülebilir. Öte yandan hasta sayısının az olması ve retrospektif bir çalışma olması bu çalışmanın kısıtlılıklarıdır. Daha çok hasta sayısını içeren prospektif çalışmalar literatüre daha çok katkı sağlayabilir.

\section{Sonuç}

Hemogram parametreleri hem yüksek centor skorunu belirlemede hem de akut tonsilofaranjitte bakteriyel-viral ayrımında kullanılabilir. Hemogram parametrelerinin modifiye centor puanlama sistemiyle birlikte kullanımı bu puanlama sisteminin duyarlılık ve özgüllüğünü arttırabilir. management of pharyngitis in children and adults. Jama. 2004;291:1587-1595.

4. Stefaniuk E, Bosacka K, Wanke-Rytt M et al. The use of rapid test QuikRead go ${ }^{\circledR}$ Strep A in bacterial pharyngotonsillitis diagnosing and therapeutic decisions. European Journal of Clinical Microbiology \& Infectious Diseases. 2017;36:1733-38.

5. Saengcharoen W, Jaisawang $P$, Udomcharoensab P et al. Appropriateness of diagnosis of streptococcal pharyngitis among Thai community pharmacists according to the 
Centor criteria. International Journal of Clinical Pharmacy. 2016;38:1318-25.

6. Acar T, Ertekin B, Girisgin AS et al. Efficiency of rapid antigen test in diagnosis of acute streptococcal tonsillopharyngitis. Clinical and Experimental Health Sciences. 2019;9:241-45.

7. Lindgren $\mathrm{C}$, Neuman MI, Monuteaux MC et al. Patient and parent-reported signs and symptoms for group A Streptococcal pharyngitis. Pediatrics. 2016;138:e20160317

8. Harris AM, Hicks LA, Qaseem A. Appropriate antibiotic use for acute respiratory tract infection in adults. Ann Intern Med. 2016;165:674.

9. Snow V, Mottur-Pilson C, Cooper RJ et al. Principles of appropriate antibiotic use for acute pharyngitis in adults. Annals of Internal Medicine. 2001;134:506-8.

10. Patel C, Green BD, Batt JM et al. Antibiotic prescribing for tonsillopharyngitis in a general practice setting. Aust $J$ Gen Pract. 2019;48:395-401.

11. Roggen I, van Berlaer G, Gordts F et al Centor criteria in children in a paediatric emergency department: for what it is worth. BMJ open. 2013;3:e002712.

12. Centor RM, Witherspoon JM, Dalton HP et al. The diagnosis of strep throat in adults in the emergency room. Medical Decision Making. 1981;1:239-46.

13. McIsaac WJ, White D, Tannenbaum D et al. A clinical score to reduce unnecessary antibiotic use in patients with sore throat. Cmaj. 1998; 158:75-83.

14. Aalbers J, O'Brien KK, Chan WS et al Predicting streptococcal pharyngitis in adults in primary care: a systematic review of the diagnostic accuracy of symptoms and signs and validation of the Centor score. $B M C$ medicine. 2011;9:1-11.

15. Shaikh N, Swaminathan N, Hooper EG. Accuracy and precision of the signs and symptoms of streptococcal pharyngitis in children: a systematic review. The Journal of Pediatrics. 2012;160:487-93. 